\title{
Common errors in access preparation by preclinical dentistry Students - A cross sectional study
}

\author{
Dr.AnumRehman ${ }^{1}$, Dr. Harsh Rajvanshi ${ }^{2}$, Dr.Reem T. Youzbaki ${ }^{3}$, \\ ${ }^{I}$ DDSAjman University of Science and Technology, UAE \\ ${ }^{2}$ BDS, Post Graduate Scholar (MPH) - Department of Public Health, Manipal University, India. \\ ${ }^{3}$ DDSDepartment of Endodontics, Ajman University of Science and Technology, UAE
}

\begin{abstract}
Introduction: Dental students undergo theoretical and practical training in pre-clinical endodontics. Once they graduate and start practicing, this training is reflected in the quality of treatment they provide. Pre clinical training helps in guiding the skills without the risk of harming health of the patients. It is important to identify the mistakes and difficulties faced by the students and correct them at this stage.

Aim: The aim of this study is to find out the common errors preclinical students make while doing access cavity preparations and how can they be minimised.

Method:2689 teeth were selected amongst 187 students and they were asked to do access cavity preparation at their own pace. The criteria for evaluation included gauging, over preparation, under preparation, floor damage, perforation, incomplete roofing, unfinished walls, lingual shoulder in case of anterior and other errors such as wrong outline and no flaring of the walls were noted.

Results: Descriptive statistics and Pearson chi square analysis was done. Statistically significant differences were observed between the type of teeth and errors done. Gouging and Other errors (Perforations, Incomplete roofs, Unfinished walls, Poor lingual shoulder) was seen in maximum anteriors $(41.26 \%$ and $20.66 \%$ respectively) followed by Overextension in lower molars (64.58\%) and Underextension in premolars (8.61\%).

Conclusion: Consideration should be given to increasing the academic understanding before students enter the clinics and student to staff interaction should also be increased.
\end{abstract}

Keywords:Access preparation; endodontics; preclinical; root canal treatment

\section{Introduction}

Dental students are given both theoretical and practical knowledge in their dental course. Practical knowledge is taught on phantom heads in order to simulate the patient's mouth which in turn provides students with procedural and motor skills which would not be possible in any other way ${ }^{(1)}$.

Endodontics has always been a challenging subject for undergrad students and this course needs development of diagnostic and practical knowledge along with clinical skills.Research on the quality of endodontic performed in preclinical and clinical years are limited.

Many studieshave suggested that the quality of the root canal treatment is particularly important due to its effect on the prognosis of the treated teeth ${ }^{(2)}$.Thus, students should understand the significance of a good access cavity preparation as it is the initial and important step in the treatment.In an ideal access, all the roofand shoulder must be removed and this is done in a straight line to the apical third of the root. An unobstructed straight line access is important for instrumentation of the canal because it decreases the risk of procedural errors and also increases the cleaning efficiency ${ }^{(3)}$.

Research has shown that there is effect of access type on the resistance of fracture, therefore and ideal access is essential for the integrity of the crown ${ }^{(4)}$. For anterior access, the amount of dentine on cingulum is important for ferrule effect for placement of restoration after RCT. Therefore, an ideal access should be adequate enough for cleaning of the canal and to preserve adequate dentine for long term survival of the restoration. A research has shown that the extend of cuspal flexure after molar access preparation has consequences for potential fracture because large restorations weakens the tooth, therefore a conservative approach should be followed ${ }^{(5)}$.

It is impossible to single out a particular factor in endodonticsresponsible for successful outcome of the therapy. Thus, we give greater importance to access because an error in the initial steps can subsequently affect the entire outcome of the treatment.

\section{Aims and Objectives}

The purpose of this study is to assess the commonest mistakes done by students during preclinical endodontic exercises and to find association between type of teeth and errors done in them. 


\section{Materials And Method}

This study was carried out by participation of students of third year in Faculty of Dentistry in Ajman university of Science and Technology.Natural teeth were preselected on the basis of availability by staff before the students started with access cavity preparation. Natural teeth have been major resource in endodontic since a long time. The purpose for using natural teeth is because of their anatomical, morphological and radiographic features. The socio demographic details and medical conditions of the patient were not known.

Table 1 below shows the shapes of the access cavity for the teeth used in the study ${ }^{(6)}$

\begin{tabular}{|l|l|l|}
\hline Tooth & Maxilla & Mandible \\
\hline Central & Triangular & Ovoid or elliptical \\
\hline Lateral & Roughly ovoid & Oval \\
\hline Canine & Oval & Oval \\
\hline First premolar & Ovoid & Ovoid \\
\hline Second Premolar & Ovoid & Ovoid \\
\hline First Molar & Triangular & Rectangular/trapezoidal \\
\hline Second Molar & Triangular & Triangular \\
\hline
\end{tabular}

Radiograph was taken for each tooth, and the teeth with receded pulp chamber, severe attrition, severe caries,extensive filling and Ellis type 2-4 fractureswere excluded. Teeth with Ellis type 1 fracture were included as they were not a threat of breakage during access cavity preparation.

2689 number of teeth were selected amongst 187students and categorised as per type of teeth (Anteriors, Premolars, Lower molars and Upper molars). The criteria for evaluation included gauging, over preparation, under preparation, floor damage, perforation, incomplete roofing, unfinished walls, lingual shoulder in case of anterior and other errors such as wrong outline and no flaring of the walls were noted.

Access cavity demonstration was given once for all groups of teeth. Students were encouraged to ask any queries related to the access of the particular tooth group.

The students were then asked to place the teeth in artificial arches and mount them inside the phantom head. They were asked to draw a grid on the tooth with a pencil, dividing the teeth into $1 / 3$ rds and do initial entry in the middle of the middle third. No time duration was allotted so the students could complete the access at their own speed.

Evaluation Guidelines were made by an endodontic specialist and when access was completed, teeth were evaluated and recorded on the tables. Chi square test was done to test the null hypothesis by checking association between groups of teeth and type of errors.

\section{Results}

Descriptive statistics and Pearson chi square analysis was done using the SPSS v22.0 by IBM. Figure 1 shows the prevalence of Gouging error in buccal, lingual, mesial and distal sides of the teeth amongst all the groups Figure 2, 3, 4 show the prevalence of overextensions, underextensions, perforations, unfinished walls, incomplete roofs, overflaring etc. Figure 5 shows other miscellaneous errors in groups of teeth. Table 1 shows the design followed for the access cavity preparation.

Pearson chi square analysis suggests the significance of type of errors compared against the group of teeth in which they were made. (Table 2)

The amount of gouging done was extensive on buccal side of anterior tooth. It could be either due to the thin buccal-lingual width of the tooth or because anterior teeth were the first teeth to be attempted by the students. Buccal gouging on the anterior and lower premolars was found and could be due to the fact that the access is done from the lingual side and therefore the bur head goes towards the buccal side.Upper molars were found to have more mesial gouging because of the location of mesial canals which are underneath the mesial marginal ridge. Upper premolars had mesial overextension because of the mesial development depression which lessens the tooth structure and becomes more prone to overextension. Another common error found was failure to remove the lingual shoulder. It could be due to the fact that lingual shoulder is difficult to locate by the students and the use of gates-glidden sometimes leads to breakage of the instrument and the student does not continue with the removal.Premolars have the most buccal and lingual underextension which could be due to the straight access to the canal which is easier to find with just a bur drop.The most common 'other error' was wrong outline. Overall, the null hypothesis was rejected. 
Figure 1 - Number and groups of teeth with Gouging errors

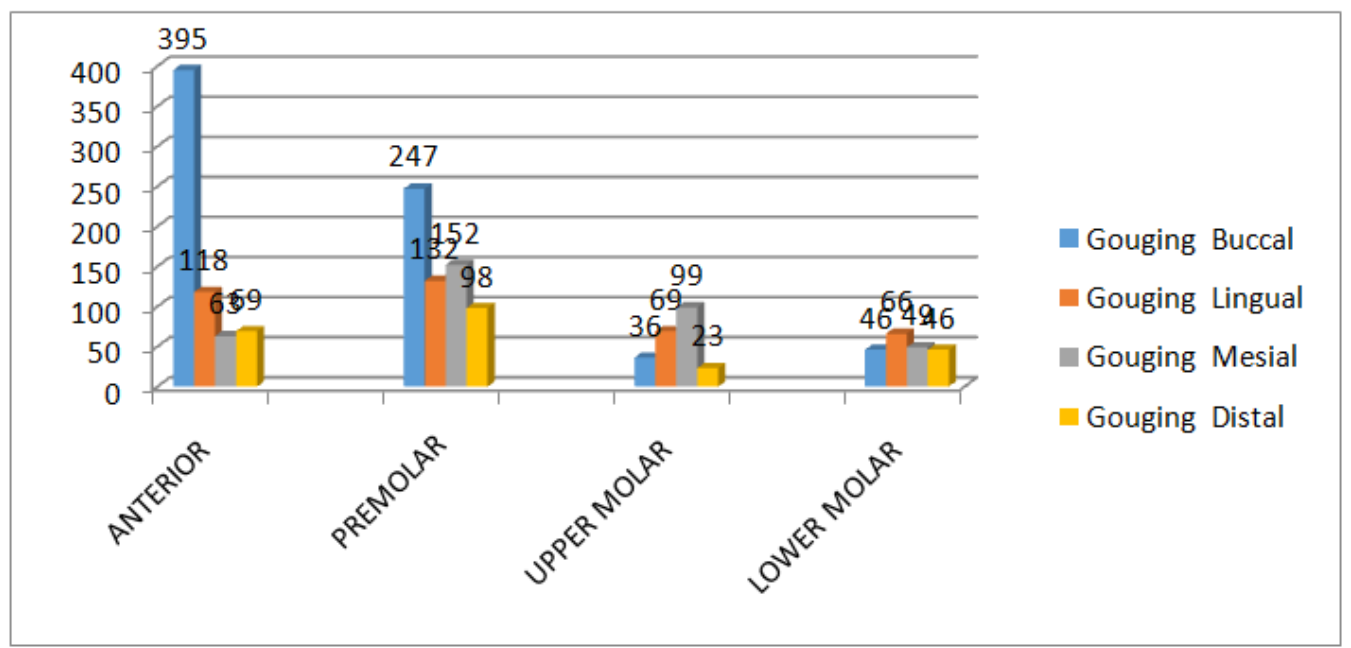

Figure 2 - Number and groups of teeth with Overextension errors

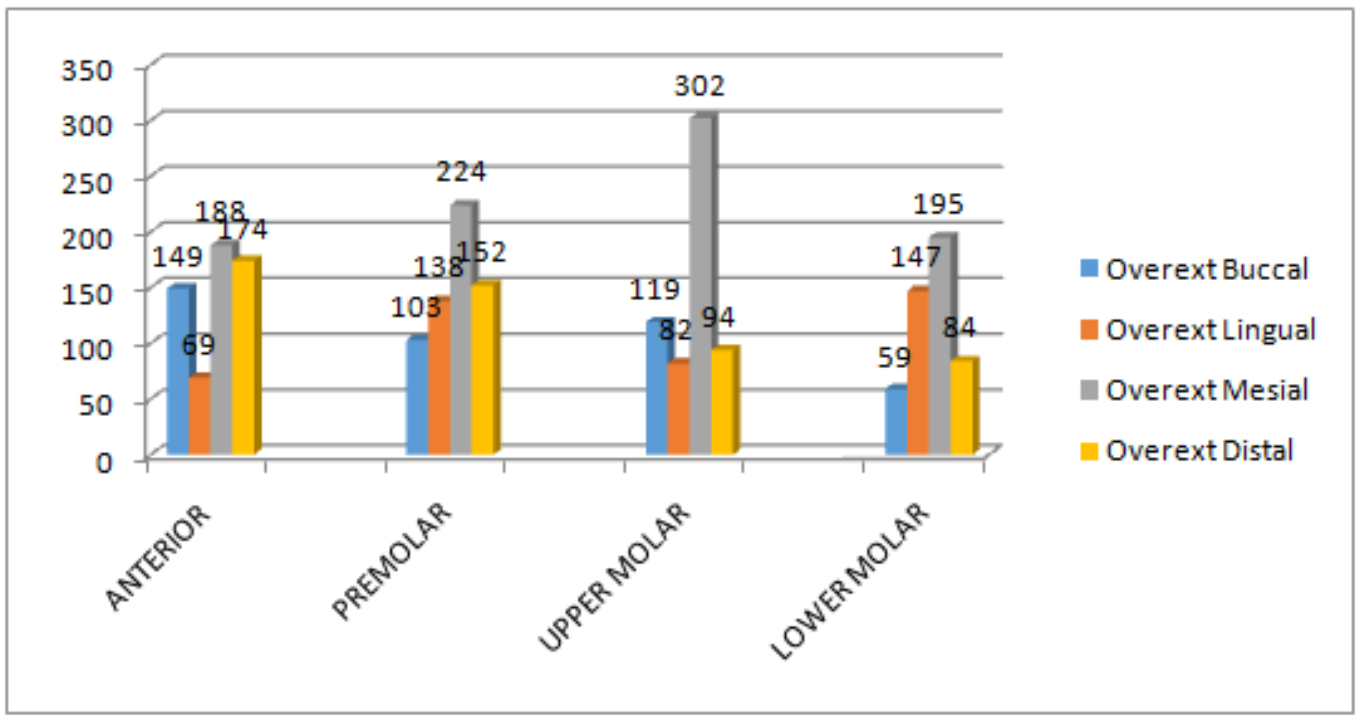

Figure 3 - Number and groups of teeth with Underextension errors

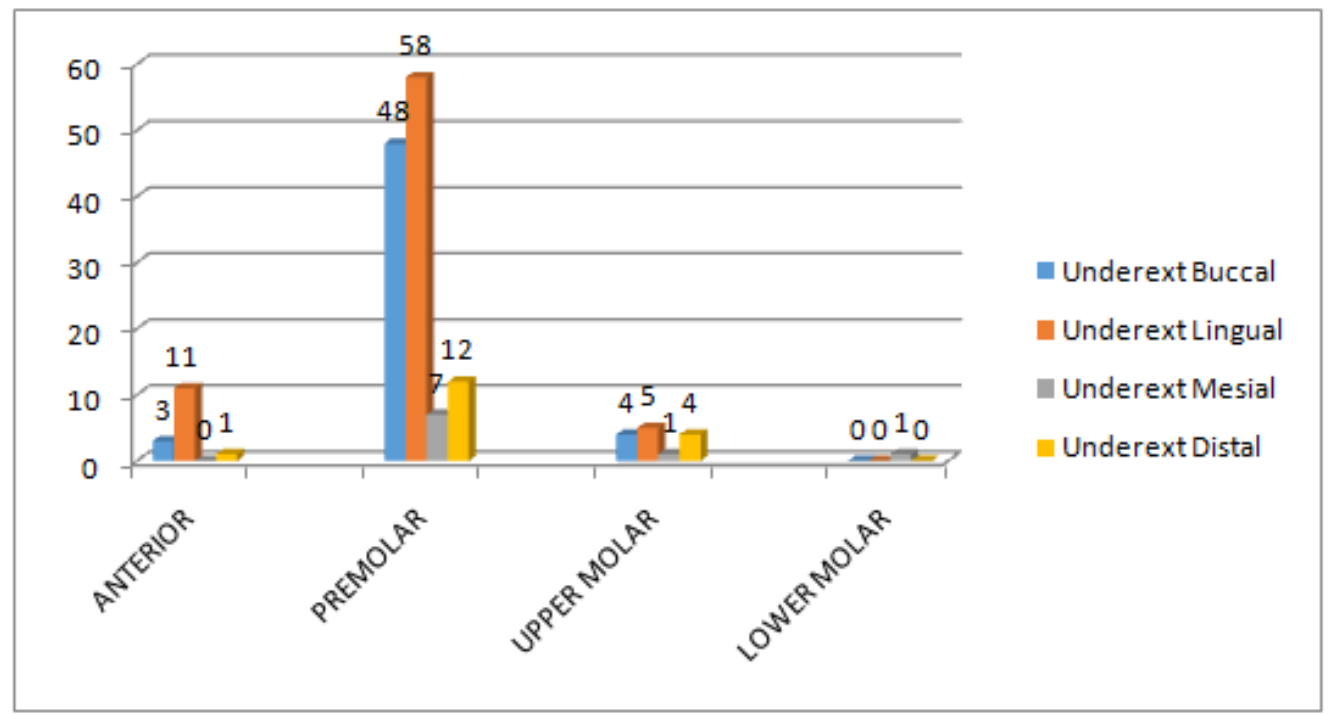


Figure 4 - Number and groups of teeth with other errors

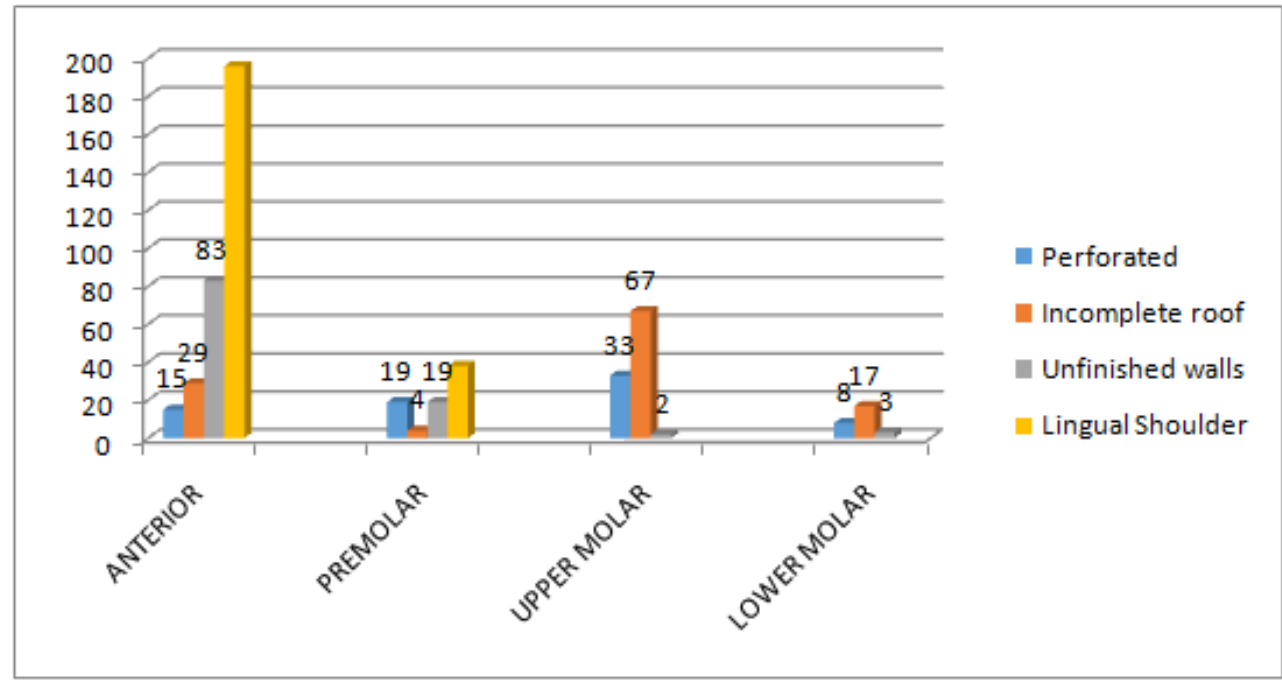

Figure 5 - Number and groups of teeth with miscellaneous errors

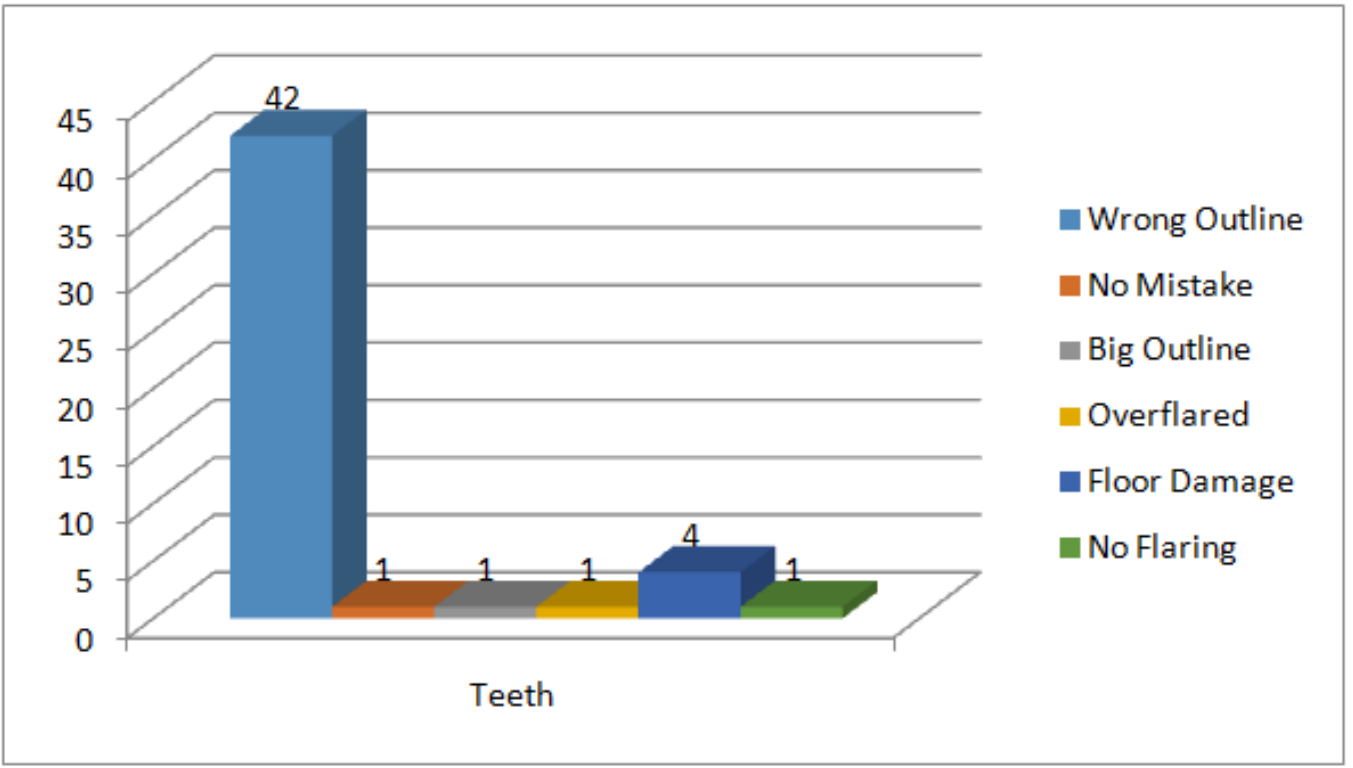

Table 2: Cross tabulation of Groups of teeth and types of errors observed

\begin{tabular}{|c|c|c|c|c|c|c|c|c|}
\hline & \multicolumn{7}{|c|}{ Type of error } & \\
\hline \multirow[t]{2}{*}{ Group of teeth } & \multicolumn{2}{|c|}{ Gouging } & \multicolumn{2}{|c|}{ Overextension } & \multicolumn{2}{|c|}{ Underextension } & \multicolumn{2}{|c|}{$\begin{array}{l}\text { Others } \\
\text { (Perforation, Incomplete roof, } \\
\text { Unfinished walls, Lingual shoulder) }\end{array}$} \\
\hline & Yes & No & Yes & No & Yes & No & Yes & No \\
\hline Anterior & $\begin{array}{l}645 \\
(41.26 \%) \\
\end{array}$ & $\begin{array}{l}918 \\
(58.74 \%) \\
\end{array}$ & $\begin{array}{l}580 \\
(37.11 \%) \\
\end{array}$ & $\begin{array}{l}983 \\
(62.89 \%) \\
\end{array}$ & $\begin{array}{l}15 \\
(0.96 \%) \\
\end{array}$ & $\begin{array}{l}1548 \\
(99.04 \%)\end{array}$ & $\begin{array}{l}323 \\
(20.66 \%)\end{array}$ & $\begin{array}{l}1240 \\
(79.34 \%) \\
\end{array}$ \\
\hline Premolar & $\begin{array}{l}429 \\
(29.56 \%)\end{array}$ & $\begin{array}{l}1022 \\
(70.44 \%)\end{array}$ & $\begin{array}{l}617 \\
(42.52 \%)\end{array}$ & $\begin{array}{l}834 \\
(57.48 \%)\end{array}$ & $\begin{array}{l}125 \\
(8.61 \%)\end{array}$ & $\begin{array}{l}1326 \\
(91.39 \%)\end{array}$ & $\begin{array}{l}80 \\
(5.51 \%)\end{array}$ & $\begin{array}{l}1371 \\
(94.49 \%)\end{array}$ \\
\hline Upper molar & $\begin{array}{l}227 \\
(24.15 \%)\end{array}$ & $\begin{array}{l}713 \\
(75.85 \%)\end{array}$ & $\begin{array}{l}597 \\
(63.51 \%)\end{array}$ & $\begin{array}{l}343 \\
(36.49 \%)\end{array}$ & $\begin{array}{l}14 \\
(1.49 \%)\end{array}$ & $\begin{array}{l}926 \\
(99.51 \%)\end{array}$ & $\begin{array}{l}102 \\
(10.85 \%)\end{array}$ & $\begin{array}{l}838 \\
(89.15 \%)\end{array}$ \\
\hline Lower molar & $\begin{array}{l}207 \\
(28.71 \%)\end{array}$ & $\begin{array}{l}514 \\
(71.29 \%)\end{array}$ & $\begin{array}{l}485 \\
(64.58 \%)\end{array}$ & $\begin{array}{l}236 \\
(5.42 \%)\end{array}$ & $\begin{array}{l}1 \\
(0.14 \%)\end{array}$ & $\begin{array}{l}720 \\
(99.86 \%)\end{array}$ & $\begin{array}{l}28 \\
(3.88 \%)\end{array}$ & $\begin{array}{l}693 \\
(96.12 \%)\end{array}$ \\
\hline
\end{tabular}

Table 3: Pearson Chi Square tests

\begin{tabular}{|l|l|l|l|}
\hline Grouping & Chi Square Value & Df & Asymp Sig. (2-sided) \\
\hline Anterior/Gouging & 22.6 & 1 & $<0.00001$ \\
\hline Anterior/Overextension & 127.27 & 1 & $<0.00001$ \\
\hline Anterior/Underextension & 40.58 & 1 & $<0.00001$ \\
\hline Anterior/Others & 199.51 & 1 & $<0.00001$ \\
\hline Premolar/Gouging & 44.06 & 1 & $<0.00001$ \\
\hline
\end{tabular}


Common errors in access preparation by preclinical dentistry students - A cross sectional study

\begin{tabular}{|l|l|l|l|}
\hline Premolar/Overextension & 32.8 & 1 & $<0.00001$ \\
\hline Premolar/Underextension & 194.5 & 1 & $<0.00001$ \\
\hline Premolar/Others & 72.2 & 1 & $<0.00001$ \\
\hline Upper molar/Gouging & 77.81 & 1 & $<0.00001$ \\
\hline Upper molar/Overextension & 102.4 & 1 & $<0.00001$ \\
\hline Upper molar/Underextension & 11.7 & 1 & $<0.000625$ \\
\hline Upper molar/Others & 0.34 & 1 & $<0.00001$ \\
\hline Lower molar/Gouging & 22.5 & 1 & $<0.00001$ \\
\hline Lower molar/Overextension & 116.9 & 1 & $<0.00001$ \\
\hline Lower molar/Underextension & 26.78 & 1 & $<0.00001$ \\
\hline Lower molar/Others & 47.64 & 1 & $<0.00001$ \\
\hline
\end{tabular}

\section{Discussion}

It has been reported that out of other mechanical phases in root canal treatment, access preparation is the most important one. There are failure rates associated with overextension and perforation because unlike under extension, overextension and perforation are irreversible and cannot be corrected ${ }^{(6)}$. Insufficient access also leads to failure as it becomes difficult to find the extra canals which remains uncleaned defying the purpose of root canal treatment ${ }^{(7)}$. Not removing all the roof may lead to consequences such as discoloration of the anterior crown or even contamination of canal space which should be properly disinfected. Therefore it is important to do ideal access preparation for successful outcome of the therapy.

The increase in the number of lab sessions does not guarantee improved learning. The important factor in improving learning skills depends on quality teaching and development of challenges ${ }^{(8)}$. Therefore a change should be introduced in the preclinical practice such as student-staff interaction where the students should identify the mistakes made during the preparation and the staff should give feedback after every teeth being accessed.

In anterior teeth a lingual approach is used as a compromise between esthetical and endodontic requirements so regardless of technology development, student should have knowledge of anatomy and core concepts therefore staff should also take oral quizzes after completion of each tooth.

Pre-operative Radiographs can be of great help as they can be assessed to determine the degree of case difficulty. Furthermore, bite-wing radiographs can give a more accurate image of the anatomy of the pulp chamber and the estimated depth of access in the posterior region ${ }^{(6)}$. So the students should be taught how to interpreta radiograph before starting a root canal therapy.

\section{Limitations}

The teeth were evaluated by a GP dentist with 6 years' experience in the endodontics field rather than a specialist. There were no microscopes used and the results mainly depended on the evaluation with the naked eye. Other limitation which was encountered during the research was difficulty in categorizing the gauging and overextension. Since there is very less difference between the two, it was then decided on the intensity of destruction made by the bur. Another problem encountered was in the difficult cases where the staff helped the students with the access preparation and therefore the whole preparation was not done by the student themselves.

\section{Conclusion}

The study provides some evidence on the common mistakes done by preclinical students and we have come to a conclusion that consideration should be given to increasing the academic understanding before the students enter the clinics.

This paper is focused on preclinical level, but an obvious complement to this study would be to examine the access preparation by students clinically on patients.

\section{Acknowledgement}

The authors are extremely thankful to the Department of Endodontics, Ajman University of Science and Technology for their cooperation. We also thank Dr. Prakash Narayanan, PhD and Dr.Ramanpreet Kaur, MBBS (MPH) for their help in the statistical analysis of this study.

\section{References}

[1]. Fugill M. Defining the purpose of phantom head. European Journal of Dental Education. 2013;17(1):e1-e4

[2]. Johnson B. Endodontic access. General dentistry. 2008;57(6):570-7; quiz 8-9, 95, 679.

[3]. Mannan G, Smallwood E, Gulabivala K. Effect of access cavity location and design on degree and distribution of instrumented root canal surface in maxillary anterior teeth. International endodontic journal. 2001;34(3):176-83.

[4]. Tang W, Wu Y, Smales RJ. Identifying and reducing risks for potential fractures in endodontically treated teeth. Journal of endodontics. 2010;36(4):609-17. 
[5]. B DM, editor Restoration of the Endodontically Treated Tooth. Practice Enhancement and Knowledge; 2008 Feb/March 2008; Canada: RCDSO.

[6]. Fouad A, Torabinejad M, Walton RE. Endodontics: principles and practice: Elsevier Health Sciences; 2008.496 p.

[7]. Barone C, Dao TT, Basrani BB, Wang N, Friedman S. Treatment outcome in endodontics: the Toronto study-phases 3, 4, and 5: apical surgery. Journal of endodontics. 2010;36(1):28-35.

[8]. Tuncel Y, Sungur, Nagas, Gorduysus. The Effectiveness Of Preclinical Demonstration Inaccess Cavity Preparation Performance. Clinical Dentistry And Research. 2014;38(1):7. 